\title{
Lead Bioavailability to Freshwater Microalgae in the Presence of Dissolved Organic Matter: Contrasting Effect of Model Humic Substances and Marsh Water Fractions Obtained by Ultrafiltration
}

\author{
Isabelle A. M. Worms ${ }^{1}$ - Vera I. Slaveykova ${ }^{1}$. \\ Kevin J. Wilkinson ${ }^{2}$
}

Received: 14 July 2014 / Accepted: 3 March 2015/Published online: 10 March 2015

(C) Springer Science+Business Media Dordrecht 2015

\begin{abstract}
Years of experimentation in well-defined media has demonstrated that trace metal bioavailability should be best predicted by the concentration (or activity) of the free cation (free ion activity model, FIAM). In the particular case of lead, uptake of $\mathrm{Pb}$ by Chlorella kessleri has been, however, shown to be higher in the presence of the Suwannee River fulvic acid and Suwannee River humic acid as compared to what was predicted by the free ion concentrations $\left[\mathrm{Pb}^{2+}\right]$. In order to estimate whether such exceptions of the FIAM can be extended to other freshwater phytoplankton, we measured the biouptake of $\mathrm{Pb}$ by $C$. reinhardtii another model phytoplankton, in solution containing these two model humic substances and for which free $\mathrm{Pb}^{2+}$ concentrations were evaluated using an ionexchange technique. Our results showed that $\mathrm{Pb}$ internalization by $C$. reinhardtii can be directly related to the $\left[\mathrm{Pb}^{2+}\right]$ but that the deviation from the FIAM when using C. kessleri was still observed under the present experimental conditions. Indeed, when using freshly isolated colloidal fraction $\left(>3 \mathrm{kDa}\right.$ ) of a marsh water and its photoaltered products, $\left[\mathrm{Pb}^{2+}\right]$ measurements are shown to poorly predict $\mathrm{Pb}$ uptake by $C$. kessleri and surprisingly $\mathrm{Pb}$ uptake by $C$. reinhardtii.
\end{abstract}

Keywords Lead - Bioavailability · Dissolved organic matter · Marsh · Chlamydomonas reinhardtii $\cdot$ Chlorella kessleri

Isabelle A. M. Worms

wormsisabelle@rocketmail.com; isabelle.worms@cea.fr

1 Environmental Biogeochemistry and Ecotoxicology, Institute F.-A. Forel, Earth and Environmental Sciences, Faculty of Sciences, University of Geneva, 10, route de Suisse, 1290 Versoix, Switzerland

2 Biophysical Environmental Chemistry, Department of Chemistry, University of Montreal, C.P. 6128, Succ. Centre Ville, Montreal, QC H3C 3J7, Canada 


\section{Introduction}

Evaluation of the fate and effects of toxic metals in ambient water is a challenging task that requires improvements in the analytical tools and modeling capacity used to predict speciation and bioavailability under environmentally relevant conditions [e.g., in the presence of dissolved organic matter (Tercier-Waeber et al. 2012)]. Years of experimentation in well-defined media, using strong metal chelators, has demonstrated that trace metal bioavailability is best predicted by the concentration (or activity) of the free cation (free ion activity model, FIAM) (Campbell 1995) or of metal fraction bound to biotic ligand (BLM) (Di Toro et al. 2001), both equilibrium-based models. According to these constructs, dissolved organic matter (DOM) is expected to reduce metal bioavailability by decreasing both the free metal concentration and the metal bound to the biotic ligand (Worms et al. 2006; Tercier-Waeber et al. 2012). For media containing humic substances, the determination of accurate free ion concentrations (or activities) is generally key to experimental verification of the conceptual models. $\mathrm{Cd}, \mathrm{Cu}$ and $\mathrm{Ni}$ bioavailability has been generally well predicted by using speciation measurements for those metals in the presence of DOM. For example, the FIAM or BLM successfully predicted Cd(II) uptake to the green algae Chlamydomonas reinhardtii (Kola and Wilkinson 2005; Vigneault and Campbell 2005), Pseudokirchneriella subcapitata (Koukal et al. 2003; Vigneault and Campbell 2005) and Chlorella kessleri (Bayen et al. 2006). Ni uptake by both $C$. reinhardtii and $C$. kessleri was shown to follow $\left[\mathrm{Ni}^{2+}\right]$ in the presence of Suwannee River humic substances (Worms et al. 2007). Similarly, in two rivers of Connecticut, $\mathrm{Cu}$ and $\mathrm{Cd}$ uptake by the diatom Stephanodiscus hantzschii and the chlorophyte $C$. vulgaris could be accounted for by variations in their chemical speciation measurements (Mylon et al. 2003). In contrast, there is a significant experimental evidence to suggest that the BLM may overestimates the protective role of $\mathrm{DOM}$ for $\mathrm{Pb}$ for which stability constant for $\mathrm{Pb}$ - $\mathrm{DOM}$ need to be corrected in the case of SRFA (Suwanee River fulvic acid, De Schamphelaere et al. 2014). In addition, $\mathrm{Pb}$ uptake by Chlorella kessleri was higher in the presence of the Suwannee River fulvic acid (SRFA) and Suwannee River humic acid (SRHA) as compared to what was predicted by the free ion concentrations (Lamelas et al. 2005; Slaveykova et al. 2003). The presence of colloidal material, isolated from a Swiss wastewater treatment plant effluent, also enhanced $\mathrm{Pb}$ uptake by $C$. kessleri (Worms et al. 2010). In contrast, for the diatom $T$. weissflogii, the cellular Pb content decreased in the presence of DOM (SanchezMarin et al. 2010a). DOM from terrestrial and riverine origin enhanced $\mathrm{Pb}$ toxicity for sea urchin embryos, the mussel Mytilus sp. and the microalga Isochrysis galbana (SanchezMarin and Beiras 2012; Sanchez-Marin et al. 2007, 2010a, 2011). The selected examples illustrate the existing controversy in our current understanding on the effects of DOM on metal bioavailability, which show that the effect is metal, phytoplankton species and DOM specific. Furthermore, it remains unclear whether the greater than predicted uptake that has been observed for $\mathrm{Pb}$ is due to the metal ligand pairing or is more related to the specific biological species that was examined.

Little is known about the effects of humic substances, other than with respect to their complexation properties in solution. In the case of microalgae, humic and fulvic acids have been shown to adsorb on micro-algal surfaces in a $\mathrm{pH}$-dependent manner, resulting in a change in the surface charge and/or membrane permeability of the algae (Campbell et al. 1997; Lamelas and Slaveykova 2007; Vigneault et al. 2000). The quality and physicochemical properties (size, hydrophobic character, complexation ability) of the humic substances depend also on their origin and can be further modified by external physical 
factors such as light (Gonsior et al. 2009; Porcal et al. 2009; Sulzberger and Durisch-Kaiser 2009). As a consequence, it has been shown that the photoalteration of humic standards reduced the increased $\mathrm{Pb}$ uptake observed for by $C$. kesslerii and improved the predictions of the equilibrium bioavailability models (Spierings et al. 2011). The direct interactions of DOM with organism surfaces plus the alteration of DOM components by such physical factors greatly mitigate our ability to quantitatively predict DOM protective role on metal toxicity.

Indeed, the first objective of this study was to account for species/metals differences observed regarding $\mathrm{Pb}$ uptake by freshwater phytoplankton. Therefore, $\mathrm{Pb}$ internalization in the presence of SRFA and SRHA was measured in two different unicellular green algae. The first used was $C$. reinhardtii for which thermodynamic models are known to predict well the uptake of metal species other than the $\mathrm{Pb}$ ones, and the second was $C$. kessleri, for which a higher than predict $\mathrm{Pb}$ uptake was previously noticed in the presence of DOM. $C$. reinhardtii species was recently shown to be more sensitive to $\mathrm{Pb}$ than $C$. kessleri (De Schamphelaere et al. 2014) and is a good model of choice for metal biosensor build up (Simon et al. 2008). Because the effect of humic substances on $\mathrm{Pb}$ uptake by $C$. reinhardtii was limited to a role of complexation (see Sect. 3), our second objective was to address whether the use of these two algal species under natural water conditions can offer a way to assess $\mathrm{DOM}$ physicochemical "indirect" effect on $\mathrm{Pb}$ uptake. Indeed, $\mathrm{Pb}$ internalization was measured in the same algal species exposed to $\mathrm{Pb}$ containing marsh water fractions isolated by ultrafiltration, and submitted or not to an artificial sunlight treatment. The materials obtained were characterized in terms of organic contents and humic properties, as well as cationic composition in order to account for water quality criteria deviations; for instance, the effect of potential metallic competitors known to affect toxic cations uptake (Worms et al. 2006).

\section{Materials and Methods}

\subsection{Experimental Solutions}

MilliQ water $\left(R>18 \mathrm{M} \Omega \mathrm{cm}\right.$, total organic carbon $\left.<2 \mu \mathrm{g} \mathrm{L}^{-1}\right)$ was used to prepare all synthetic media. Solutions were buffered to $\mathrm{pH} 6$ using $10^{-2} \mathrm{M} 2$-[N-morpholino] ethanesulfonate (MES, Sigma). Lead was added to the solutions by dilution of a $1000 \mathrm{mg} \mathrm{L}^{-1} \mathrm{~Pb}\left(\mathrm{NO}_{3}\right)_{2}$ standard solution (Fluka). Well-characterized, standard aquatic fulvic (SRFA) and humic acids (SRHA), isolated from the Suwannee River in Georgia, were obtained from the International Humic Substances Society. One $\mathrm{g} \mathrm{L}^{-1}$ stock solutions of the lyophilized humic substances was prepared in MilliQ water, adjusted to $\mathrm{pH} 9.0$ with $\mathrm{NaOH}$ and left overnight (dark, $4{ }^{\circ} \mathrm{C}$ ) to equilibrate. Additional exposure experiments were performed with water sampled from Laconnex marsh, which is located $10 \mathrm{~km}$ west of Geneva. Marsh water was collected in a 20 -L polycarbonate carboy that was washed successively with $0.1 \mathrm{M} \mathrm{NaOH}, 0.1 \mathrm{M} \mathrm{HCl}$ and ultrapure water in order to decrease both metal and DOM contamination. Samples were filtered through a $0.45-\mu \mathrm{m}$ PVDF filters, washed using the same protocol than the carboy, before being concentrated to $2 \mathrm{~L}$ using a Pellicon XL 3-kDa cutoff membrane (Millipore), according to a previously described procedure (Kottelat et al. 2008). The $2 \mathrm{~L}$ of retentate and the flow-through water are hereafter called colloidal concentrate (Col) and ultrafiltered water (UF), respectively. A portion of the Col sample was treated under full solar simulated light for $12 \mathrm{~h}$ at a low 
Table 1 Composition and major characteristics of sample fractions isolated from the Laconnex marsh: Col (retentate); $\mathrm{Col}^{*}$ (photoirradiated retentate); UF (ultrafiltrate)

\begin{tabular}{|c|c|c|c|}
\hline & $\mathrm{Col}$ & $\mathrm{Col}^{*}$ & UF \\
\hline \multicolumn{4}{|c|}{ Total major metal concentrations, ICP-OES (Optima 3300DV, PerkinElmer) } \\
\hline $\mathrm{Ca}\left(\mathrm{mg} \mathrm{L}^{-1}\right)$ & $98.8 \pm 1.0$ & $72.1 \pm 0.3$ & $107.6 \pm 0.2$ \\
\hline $\operatorname{Mg}\left(\mathrm{mg} \mathrm{L}^{-1}\right)$ & $7.86 \pm 0.03$ & $8.65 \pm 0.07$ & $7.92 \pm 0.06$ \\
\hline $\mathrm{Na}\left(\mathrm{mg} \mathrm{L}^{-1}\right)$ & $4.68 \pm 0.08$ & $4.9 \pm 0.7$ & $4.40 \pm 0.05$ \\
\hline $\mathrm{K}\left(\mathrm{mg} \mathrm{L}^{-1}\right)$ & $3.05 \pm 0.07$ & $3.20 \pm 0.05$ & $3.0 \pm 0.2$ \\
\hline \multicolumn{4}{|c|}{ Total trace metal concentrations, ICP-MS (Elan DRCII, PerkinElmer) } \\
\hline $\operatorname{Mn}(\mu \mathrm{M})$ & $1.07 \pm 0.03$ & $0.44 \pm 0.05$ & $10.2 \pm 0.3$ \\
\hline $\mathrm{Fe}(\mu \mathrm{M})$ & $3.8 \pm 0.3$ & $3.4 \pm 0.2$ & $3.1 \pm 0.3$ \\
\hline $\mathrm{Ni}(\mathrm{nM})$ & $223.6 \pm 8.4$ & $198.5 \pm 10.6$ & $247.1 \pm 12.9$ \\
\hline $\mathrm{Cu}(\mathrm{nM})$ & $75.1 \pm 6.2$ & $108.9 \pm 4.9$ & $18.7 \pm 9.5$ \\
\hline $\mathrm{Zn}(\mathrm{nM})$ & $45.0 \pm 0.8$ & $52.8 \pm 0.5$ & $62.3 \pm 0.4$ \\
\hline Co (nM) & $9.8 \pm 0.8$ & $9.6 \pm 0.2$ & $6.2 \pm 0.1$ \\
\hline $\mathrm{Cd}(\mathrm{nM})$ & $0.097 \pm 0.022$ & $0.094 \pm 0.032$ & $0.12 \pm 0.03$ \\
\hline $\mathrm{Pb}(\mathrm{nM})$ & $1.65 \pm 0.18$ & $4.55 \pm 0.19$ & $0.78 \pm 0.47$ \\
\hline
\end{tabular}

Total organic carbon and total nitrogen concentrations (TOC-V CPA, Shimadzu Scientific Instrument)

$\begin{array}{llll}\text { TOC }\left(\mathrm{mg} \mathrm{L}^{-1}\right) & 15.4 & 16.0 & 5.4 \\ \text { TN }\left(\mathrm{mg} \mathrm{L}^{-1}\right) & 1.1 & 1.3 & 0.2 \\ \text { TOC/TN ratio } & 14 & 12.2 & 27\end{array}$

Inorganic anion concentrations (ionic chromatography, Dionex)

$\begin{array}{llll}\mathrm{Cl}(\mathrm{mM}) & 6.5 & 7.5 & 6.6 \\ \mathrm{NO}_{3}(\mathrm{mM}) & 0.30 & 0.65 & 0.15 \\ \mathrm{SO}_{4}(\mathrm{mM}) & 15.1 & 16.9 & 12.3\end{array}$

Fluorescence characterization (Luminescence Spectrometer LS 55, PerkinElmer)

Emission/excitation matrix (EEM)

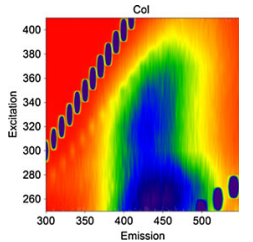

Intensity peak $\mathrm{A}^{\mathrm{a}}$

Intensity peak $\mathrm{C}^{\mathrm{a}}$

Fluorescence index ${ }^{b}$

Humification index ${ }^{c}$

$$
\begin{aligned}
& 26.4 \pm 1.5 \\
& 19.2 \pm 1.6 \\
& 1.78 \pm 0.07 \\
& 18.3 \pm 2.1
\end{aligned}
$$

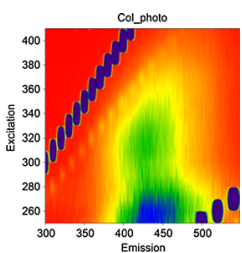

$$
17.6 \pm 1.1
$$$$
13.0 \pm 1.1
$$$$
1.84 \pm 0.08
$$$$
13.5 \pm 1.6
$$

Charges on ions have been omitted for simplicity. The instrumentation used for the measurements has been indicated in the table

${ }^{\text {a }}$ Peak A $\left(\mathrm{Em}_{\max }=445 \mathrm{~nm}\right.$ at $\left.\mathrm{Ex}_{\max }=260 \mathrm{~nm}\right)$ and peak $\mathrm{C}\left(\mathrm{Em}_{\max }=445 \mathrm{~nm}\right.$ at $\left.\mathrm{Ex}_{\max }=320 \mathrm{~nm}\right)$ are defined, respectively, as the humic or fulvic-specific signature (Coble 1996)

${ }^{\mathrm{b}}$ Fluorescence index, $\mathrm{FI}=\mathrm{Em}_{450} / \mathrm{Em}_{500}$ using an excitation at $350 \mathrm{~nm}\left(\mathrm{Ex}_{350}\right)$ provides information on the origin of the humic substances (McKnight et al. 2001)

c Humification index, $\mathrm{HI}=\Sigma \mathrm{Em}_{435-480} / \Sigma \mathrm{Em}_{300-345}$ at $\mathrm{Ex}_{254}$, reflects the degree of condensation of the humic substances (Zsolnay et al. 1999). Values of HI for the SRHA and the SRFA are of 21.3 and 9.5, respectively (Worms et al. 2015) 
energy of $7 \times 10^{6} \mathrm{~J} \mathrm{~m}^{-2}$ (Sun 2000, Abet Technologies). The major components (organic and inorganic) of each of the three marsh fractions (Col, UF, photoirradiated $\mathrm{Col}=\mathrm{Col}^{*}$ ) are summarized in Table 1. Each water fraction was buffered at $\mathrm{pH} 7 \mathrm{using} 5 \times 10^{-3} \mathrm{M}$ of 4-(2-hydroxyethyl)-1-piperazineethanesulfonic acid (HEPES, Sigma).

\section{2 $\mathrm{Pb}($ II) Speciation}

$\mathrm{Pb}$ speciation was calculated using either $\mathrm{MINEQL}^{+}$(version 3.01b) (Schecher and McAvoy 1992) or VisualMINTEQ (version 3.1), using default database of the NICADonnan approach to evaluate complexation by the humic substances (Guftavsson 2006). Stability constants, $K$, were updated using the NIST (National Institute of Standards and Technology) database for citric acid and corrected to ionic strength $I=0$ using the Davies equation. Equilibrium calculations were verified by measuring $\left[\mathrm{Pb}^{2+}\right]$ using an ion-exchange technique (IET) (Cantwell et al. 1982; Fortin and Campbell 1998; Worms and Wilkinson 2008). In brief, solutions were equilibrated with columns containing $50 \mathrm{mg}$ of

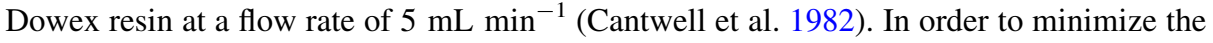
volumes (and times) required to reach equilibrium, $\mathrm{NaNO}_{3}$ was added to the experimental solutions to give a final ionic strength of $0.1 \mathrm{M}$ (increase of ten times compared to the initial value). Under these conditions, a 30-min equilibration time, corresponding to $150 \mathrm{~mL}$ of experimental solution, was required. Metal adsorbed to the resin was eluted using $5 \mathrm{~mL}$ of $1.5 \mathrm{M} \mathrm{HNO}_{3}$ at a flow rate of $0.5 \mathrm{~mL} \mathrm{~min}^{-1}$ (Fortin and Campbell 1998). Free $\mathrm{Pb}$ concentrations were determined from the concentration of lead eluted from the resin, $[\mathrm{Pb}]_{\mathrm{el}}$, using a partition coefficients, $\lambda_{\mathrm{Pb}}\left(\mathrm{L} \mathrm{g}^{-1}\right)$ that was obtained from the calibration of standard solutions containing no ligand prepared in MES buffered at $\mathrm{pH} 6$ (Eq. 1):

$$
\left[\mathrm{Pb}^{2+}\right]=\frac{[\mathrm{Pb}]_{\mathrm{el}} \times V_{\mathrm{el}}}{\lambda \times m_{\mathrm{res}}}
$$

where $m_{\text {res }}(\mathrm{g})$ is the mass of the resin that was used and $V_{\mathrm{el}}(\mathrm{L})$ is the volume of acid used to elute the $\mathrm{Pb}$ (evaluated by weighing the receiving tube before and after elution). Average conditional stability constants for the metal humic complexes, $K_{\mathrm{M}-\mathrm{HS}}$, were estimated by assuming that complexing sites were in large excess to the metal and that a one-to-one complex was formed (Lamelas et al. 2005). Since phenolic groups should all be protonated at $\mathrm{pH} 6$, constants were determined from the slopes of the plots of the degree of complexation, $[\mathrm{M}]_{\mathrm{tot}} /\left[\mathrm{M}^{2+}\right]$, as a function of the concentration of carboxylic acid functional groups, $\left[\mathrm{COO}^{-}\right]$(Eq. 2):

$$
\frac{[\mathrm{M}]_{\mathrm{tot}}}{\left[\mathrm{M}^{2+}\right]}=1+K_{\mathrm{M}-\mathrm{HS}}\left[\mathrm{COO}^{-}\right]
$$

Based on titration studies, $\left[\mathrm{COO}^{-}\right]=6.6 \times 10^{-3} \mathrm{~mol} \mathrm{~g}^{-1}$ for the SRFA and $4.9 \times 10^{-3} \mathrm{~mol} \mathrm{~g}^{-1}$ for the SRHA at pH 6 (Ritchie and Perdue 2003). Constants were corrected to $I=10^{-2} \mathrm{M}$ using the Davies equation (Jumarie et al. 2001) and assuming that humic substances behave like monodentate ligands. The free ion was then determined manually for each conditions. To ensure reproducibility, duplicate columns were run simultaneously for each sample.

For marsh water ultrafiltration fractions, a total concentration of $[\mathrm{Pb}]_{\mathrm{tot}}=10^{-7} \mathrm{M}$ was added and ionic strength increase to $0.1 \mathrm{M}$ using $\mathrm{NaNO}_{3}$ salt before speciation was estimated. Free $\mathrm{Pb}$ concentrations were obtained from a procedure previously described by 
Worms and Wilkinson (2008), which was based on the use of the Pb partition coefficients $\left(\lambda_{\mathrm{Pb}}\right)$ and a correction for Ca competition. Calibrations were performed using solutions that had the same cationic composition as the natural water fractions (including the $5 \times 10^{-3} \mathrm{M}$ HEPES, pH 7) with increasing [Ca $]_{\text {tot }}$ and a constant $[\mathrm{Pb}]_{\mathrm{tot}}=5 \times 10^{-8} \mathrm{M}$. This procedure has been recently validated for determinations of $\mathrm{Pb}$ speciation in model solutions and soil extracts (Hajdu and Slaveykova 2012). Under our conditions, the contribution of inorganic $\mathrm{Pb}$ species to other than $\mathrm{Pb}^{2+}(11-25 \%$ or total $\mathrm{Pb}$ at maximum depending on the presence of organic ligands) to measured $[\mathrm{Pb}]_{\mathrm{el}}$ were neglected, leading to some but minor uncertainty in the determination of $\left[\mathrm{Pb}^{2+}\right]$.

\subsection{Algal Bioassays}

Chlamydomonas reinhardtii, wild type $2137 \mathrm{mt}+$, was obtained from Prof. Michel Goldschmidt-Clermont (University of Geneva). The algae were transferred from a weekold tris-acetate-phosphate (TAP) (Harris 1989) agar plate into a $(4 \times)$ diluted TAP solution $\left(I=10^{-2} \mathrm{M}\right)$ (Kola and Wilkinson 2005). Cells were grown to a density of $(2-3) \times 10^{6}$ cells $\mathrm{mL}^{-1}$ using a 12 -h light $\left(50 \mu \mathrm{mol}\right.$ photons $\left.\mathrm{m}^{-2} \mathrm{~s}^{-1}\right) / 12$-h dark regime at $20{ }^{\circ} \mathrm{C}$ (100 rpm mixing, Infors Multitron incubator). Cells were then diluted into fresh media to give $(1-2) \times 10^{5}$ cells $\mathrm{mL}^{-1}$. After two more days of growth, corresponding to the late logarithmic growth phase $\left[(1-2) \times 10^{6}\right.$ cells $\left.\mathrm{mL}^{-1}\right]$, cells were harvested by lowspeed centrifugation $(1000 \times \mathrm{g}, 3 \mathrm{~min})$ in 50 -mL sterile (polypropylene) tubes then resuspended in the same volume of $10^{-2} \mathrm{M}$ NaMES and centrifuged again $(2 \times)$. Finally, cells were transferred to the $\mathrm{Pb}$ containing experimental media (see below) at a final cell concentration of $(2-5) \times 10^{5}$ cells $\mathrm{mL}^{-1}$, corresponding to a final cell density of $0.8-1.2 \mathrm{~cm}^{2} \mathrm{~mL}^{-1}$.

C. kessleri (strain 266 from the Canadian Phycological Culture Center, Department of Biology, University of Waterloo, Canada) were cultured in OECD (Organization for Economic Cooperation and Development) media (OECD 1984), to its mid-exponential growth phase, at which it was harvested by gentle filtration, washed $\left(5 \mathrm{~mL} 10^{-2} \mathrm{M}\right.$ NaMES, $3 \times$ ) and transferred to the experimental media at a final cell surface density of $3.0-3.8 \mathrm{~cm}^{2} \mathrm{~mL}^{-1}$ (Slaveykova and Wilkinson 2002). For water fraction isolated from the marsh, the protocol used to harvest the cells was identical except for the wash buffer that was $5 \times 10^{-3}$ M HEPES, pH 7 to match $\mathrm{pH}$ used.

$\mathrm{Pb}$ bioavailability was characterized by uptake fluxes or intracellular lead contents, which were determined in short-term experiments that were designed to reduce the possible production of exudates that could led to a modification of in $\mathrm{Pb}$ speciation (Kola et al. 2004). Following a 30-min exposure to an experimental medium containing a precisely determined free $\mathrm{Pb}$ concentration, $10^{-3} \mathrm{M}$ of ethylendiamine tetraacetic acid (EDTA, Sigma-Aldrich) was added to stop biouptake (Hassler et al. 2004). Algae were separated by a 3-min centrifugation at $2700 \times g$ and then washed twice with $30 \mathrm{~mL}$ of $10^{-2} \mathrm{M}$ NaMES. The final pellet was digested in $0.3 \mathrm{~mL}$ of concentrated, suprapure $\mathrm{HNO}_{3}$ (J.T. Baker) and digested at $100{ }^{\circ} \mathrm{C}$ for a minimum of $2 \mathrm{~h}$. Internalization fluxes $\left(J_{\text {int }}, \mathrm{mol} \mathrm{cm}^{-2} \mathrm{~s}^{-1}\right)$ were calculated by dividing intracellular lead by the time of exposition.

Cell numbers and surface areas were determined by a Coulter Multisizer II or III particle counter (Beckman-Coulter). All culture media and experimental solutions were sterilized (autoclave, $0.2-\mu \mathrm{m}$ filtration) prior to use. All manipulations of algal cultures were performed under laminar flow conditions (Heraeus, Germany), and all bottle borders were flame sterilized. 


\section{Results and Discussion}

\subsection{Pb Complexation by SRFA and SRHA Using an Equilibrium Ion- Exchange Technique}

In the presence of $10^{-5} \mathrm{M} \mathrm{Ca}^{2+}$ and $0.1 \mathrm{M} \mathrm{NaNO}_{3}$, a partition coefficient of $(2.8 \pm 0.2) \mathrm{g} \mathrm{L}^{-1}$ was determined for the ion-exchange resin, which is approximately $2 \times$ the value observed for $\mathrm{Ni}$ under the similar conditions, $\lambda_{\mathrm{Ni}}=(1.47 \pm 0.02) \mathrm{L} \mathrm{g}^{-1}$ (Worms and Wilkinson 2008). The difference in resin affinity has previously been shown to decrease in the order $\lambda_{\mathrm{Pb}}>\lambda_{\mathrm{Cu}}>\lambda_{\mathrm{Cd}}$ with values ranging from 1.2 to $0.78 \mathrm{~g} \mathrm{~L}^{-1}$ for studies performed in $10^{-2} \mathrm{M} \mathrm{NaNO}_{3}$ at $\mathrm{pH} 6$ (Ge et al. 2005). For experiments performed in $0.2 \mathrm{M} \mathrm{NaNO}_{3}$ at $\mathrm{pH} 7, \lambda_{\mathrm{Cd}}$ was found to be $(0.55 \pm 0.03) \mathrm{g} \mathrm{L}^{-1}$ for (Fortin and Campbell 1998; Fortin and Caron 2000). As the concentrations of the humic substances were increased from 0 to $20 \mathrm{mg} \mathrm{L}^{-1},\left[\mathrm{~Pb}^{2+}\right]$ decreased (Fig. 1, dots). For example, in the presence of $10 \mathrm{mg} \mathrm{L}^{-1} \mathrm{DOM}$ at $\mathrm{pH} 6,75 \%$ of the $\mathrm{Pb}$ was complexed by the SRFA and $87 \%$ was complexed by the SRHA, results very different to values were obtained using Visual MINTEQ with its default NICA-Donnan parameters. Indeed, Visual MINTEQ

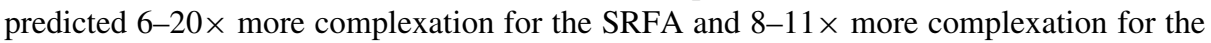
SRHA (Fig. 1, lines). This discrepancy (with an average fold of 4.7) in the estimation of free $\mathrm{Pb}$ compared to measured values was recently reported for SRFA by De Schamphelaere et al. (2014) while using the same software.

In order to correct complexation data obtained at $I=0.1 \mathrm{M}$ to the lower ionic strength $(I=0.01 \mathrm{M})$ that was used in the algal exposure experiments, conditional stability constants were evaluated on the basis of a single carboxylic complexing site (i.e., phenolic groups are likely to be protonated at $\mathrm{pH}$ 6). Conditional stability constants of $K_{\text {SRFA-Pb }}=10^{4.6} \mathrm{M}^{-1}$ and $K_{\text {SRHA-Pb }}=10^{5.2} \mathrm{M}^{-1}$ were obtained for the interactions between the $\mathrm{Pb}$ and the humic, which corresponded to $K_{\mathrm{SRFA}-\mathrm{Pb}}=10^{5.4} \mathrm{M}^{-1}$ and $K_{\mathrm{SRHA}-\mathrm{Pb}}=10^{5.9} \mathrm{M}^{-1}$ after correction to $I=0$ using the Davies equation $(b=0.2)$. These results are consistent with conditional stability constants of $K_{\text {SRFA-Pb }}=10^{6-5.2}$ and

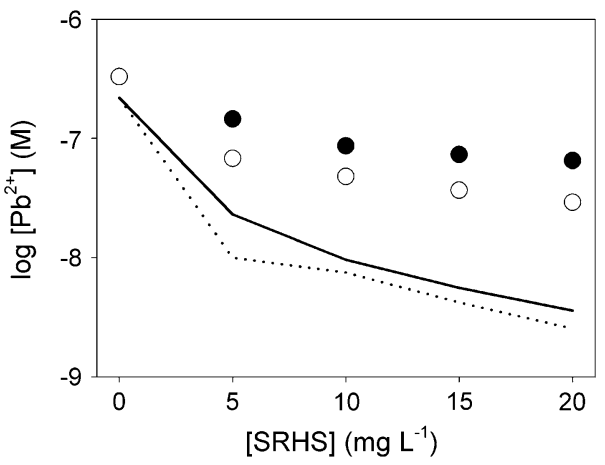

Fig. 1 Comparison between measured (dots) and calculated (lines) $\left[\mathrm{Pb}^{2+}\right]$ in the presence of SRFA (black circles, full line) or SRHA (white circles, dotted line) ranging from 0 to $20 \mathrm{mg} \mathrm{L}^{-1}$ in the presence of $10^{-5} \mathrm{M} \mathrm{Ca}^{2+}$ in $10^{-2} \mathrm{M}$ NaMES, pH $6, I=0.1 \mathrm{M}\left(\mathrm{NaNO}_{3}\right)$. Standard deviations $(n=3)$ are given when larger than the symbol size. $\left[\mathrm{Pb}^{2+}\right]$ was calculated by the NICA-Donnan model in Visual MINTEQ using default parameters 
$K_{\text {SRHA-Pb }}=10^{6} \mathrm{M}^{-1}$ obtained previously using a $\mathrm{Pb}^{2+}$ selective electrode at $I=5 \times 10^{-3} \mathrm{M}$ and pH 6 (Lamelas et al. 2005; Slaveykova et al. 2003).

\subsection{Pb Availability to Algae in the Presence or Absence of the Model Humic Substances}

Internalization increased linearly over time for short-term exposures (Fig. 2, inset), and thus, internalization fluxes $\left(J_{\text {int }}\right)$ were determined from the bioaccumulation data taken at $30 \mathrm{~min}$. C. reinhardtii was exposed to solutions containing various concentrations of SRHA or SRFA (from 0 to $20 \mathrm{mg} \mathrm{L}^{-1}$ ) in the presence of $1 \times 10^{-7}$ or $5 \times 10^{-8} \mathrm{M}$ $[\mathrm{Pb}]_{\text {tot }}$. For each set of experiments, algae were also exposed to solutions containing known concentrations of $\mathrm{Pb}^{2+}$, in order to verify the validity of the free ion activity model.

$\mathrm{On}$ a $\log -\log$ scale, $\mathrm{Pb}$ internalization fluxes were linearly related to the concentrations of $\mathrm{Pb}^{2+}$ determined by the IET, implying that the humic substances played only a role of $\mathrm{Pb}$ complexant under our conditions (Fig. 2). No effect other than a decrease in uptake was noticed while increasing concentration of humic substances. Indeed, for $C$. reinhardtii, the bioavailability of $\mathrm{Pb}$ should be predicted based on the free ion in solution, result that is consistent with those obtained with other metals: Ni (Worms et al. 2007) and Cd (Kola and Wilkinson 2005; Vigneault and Campbell 2005).

Previous results by our group using $C$. kessleri and a near-identical experimental protocol showed a significant increase in biouptake of $\sim 7 \times$ in the presence of $[\mathrm{SRFA}]=20 \mathrm{mg} \mathrm{L}^{-1} \quad$ (Slaveykova et al. 2003) and $\sim 10 \times$ in the presence of [SRHA] $=10 \mathrm{mg} \mathrm{L}^{-1}$ (Lamelas et al. 2009), leading us to believe that (biological) species differences are important in determining the interaction of the $\mathrm{Pb}^{2+}$ and humic substances with the cell. The only chemical differences between the two studies were the presence of $1 \times 10^{-5} \mathrm{M} \mathrm{Ca}$ here and the use of a slightly higher ionic strength. Therefore, an additional experiment was performed using C. kessleri and the addition of $10^{-5} \mathrm{M}$ Ca to the experimental medium. $\mathrm{Pb}$ concentrations were varied for a constant concentration of SRFA or SRHA (10 $\mathrm{mg} \mathrm{L}^{-1}$ ) (Fig. 3). The addition of $10^{-5} \mathrm{M}$ Ca had little impact on $\mathrm{Pb}$ biouptake by $C$. kessleri in the presence of $10 \mathrm{mg} \mathrm{L}^{-1}$ SRHA or SRFA (contrast red and black bars in Fig. 3). Furthermore, for solutions containing $10 \mathrm{mg} \mathrm{L}^{-1} \mathrm{SRFA}, \mathrm{Pb}$ uptake in the presence or absence of $\mathrm{Ca}$ was well predicted on the basis of $\left[\mathrm{Pb}^{2+}\right]$ alone. On the other hand, measured internalization fluxes obtained in the presence of the SRHA were higher than those predicted on the basis of the free ion only (white circles). As previously

Fig. 2 Logarithmic relationship between free $\mathrm{Pb}$ measured by the IET and internalization fluxes obtained for $C$. reinhardtii. Experiments are performed in the absence (open circle) or the presence of $10^{-5} \mathrm{M}$ citrate (open square) and 5-20 $\mathrm{mg} \mathrm{L}^{-1}$ of SRFA (filled circle) or SRHA (filled square) for total $\mathrm{Pb}$ concentrations of $1 \times 10^{-7}$ or $5 \times 10^{-8} \mathrm{M},\left[\mathrm{Ca}^{2+}\right]=10^{-5} \mathrm{M}$, $10^{-2} \mathrm{M}$ NaMES, pH 6

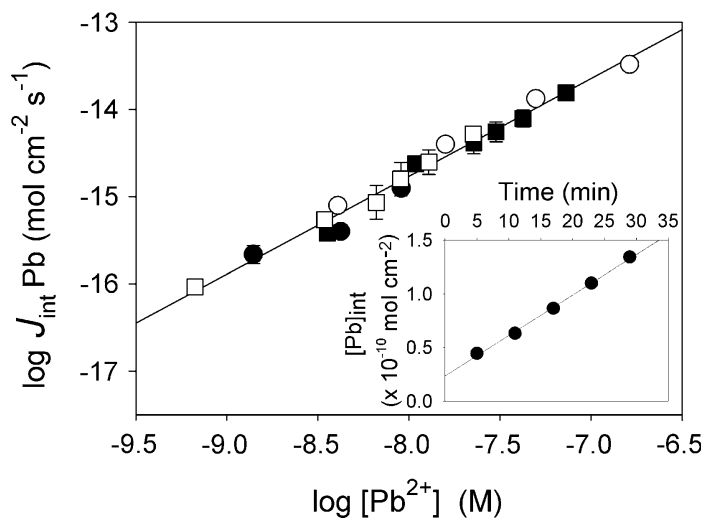




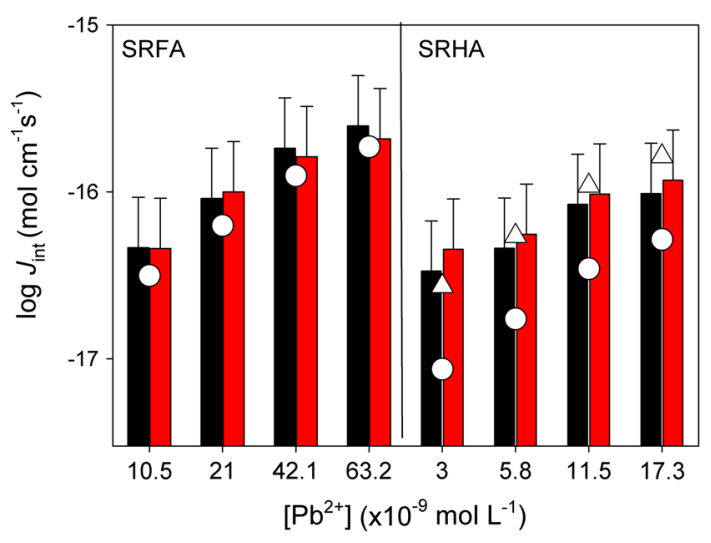

Fig. 3 Effect of $\mathrm{Ca}$ on the internalization flux of $\mathrm{Pb}$ by Chlorella kessleri. Experiments are performed for increasing $\mathrm{Pb}$ concentrations in the absence (black bars) or presence (red bars) of $10^{-5} \mathrm{M} \mathrm{Ca}$ in an experimental medium containing $10^{-2} \mathrm{M}$ NaMES (pH 6) and $10 \mathrm{mg} \mathrm{L}^{-1}$ SRHA or SRFA. Internalization fluxes are modeled by taking into account the interaction of $\mathrm{Pb}^{2+}$ only (white circles) or by also taking into account the formation of a ternary complex, SRHA-Pb-Rs (white triangles). $\left[\mathrm{Pb}^{2+}\right]$ on the $x$-axis was determined by IET

postulated (Lamelas et al. 2005; Lamelas and Slaveykova 2007; Lamelas et al. 2009), part of the SRHA-Pb complexes could be bioavailable thanks to the formation a ternary complex (SRHA-Pb-Rs) at the site of metal transport (Rs), leading to the uptake of the $\mathrm{Pb}$ cation free of ligand but leading to an enhanced uptake of the metal. In order to quantitatively account for such increase, the participation of Pb-SRHA complexes to the global internalization process was simulated using a prepublished stability constant of $K_{\mathrm{SRHA}-\mathrm{Pb}-}$ Rs, of $10^{4.5} \mathrm{M}^{-1}{ }^{1}$ Results obtained under our conditions (white triangles in Fig. 3 correspond to modeling results that take into account the formation of a ternary complex) were well predicted while using this model, comforting the hypothesis of the SRHA-Pb-Rs complex formation for $C$. keslerii. From these results, it is clear that the increase in $\mathrm{Pb}$ bioavailability observed in the presence of humic substances was largely dependent upon the algal species examined.

With respect to the biological differences, in the absence of humic substances, $\mathrm{Pb}$ internalization fluxes were two orders of magnitude higher for $C$. reinhardtii than for Chlorella kessleri (Slaveykova and Wilkinson 2002), in line with results obtained for Cd and Ni (Bayen et al. 2006; Vigneault and Campbell 2005; Worms et al. 2007). Internalization is thought to limit biouptake for both strains, since the maximum diffusive flux for $\mathrm{Pb}\left(J_{\text {diff }}\right)$ was at least three orders magnitude larger than the $\mathrm{Pb}$ internalization flux $\left(J_{\text {int }}\right)$ for C. reinhardtii and five orders of magnitude larger than that observed for C. kessleri (Van Leeuwen 1999; van Leeuwen et al. 2005). Nonetheless, in a recent study, the high uptake fluxes for $C$. reinhardtii were hypothesized to have led to a diffusive limitation of the uptake of $\mathrm{Pb}$ carbonato-complexes for this alga. In that case, in the presence of the carbonato-complexes, $\mathrm{Pb}$ uptake was also higher than could be predicted from the free $\mathrm{Pb}$ concentrations and not observed for C. kessleri (Sanchez-Marin et al. 2013). Since the first interaction of the metals is with the cell wall, the possibility that it might be responsible for

1 A value of $10^{4.5}$ rather than $10^{4.7} \mathrm{M}^{-1}$ (Lamelas et al. 2005) was used to account for differences in ionic strength. 
some of the above differences was examined. The cell wall of $C$. reinhardtii is composed of a 200-nm-thick network composed primarily of histidine-rich glycoproteins and structured in a multilayer fashion (Goodenough and Heuser 1985). In contrast, the cell wall of Chlorella kessleri is mainly composed of cellulosic residues with a thickness of $\sim 55 \mathrm{~nm}$ (Yamamoto et al. 2005). Electrophoretic mobility values of $-1 \times 10^{-8} \mathrm{~m}^{2} \mathrm{~V}^{-1} \mathrm{~s}^{-1}$ have been reported for $C$. reinhardtii at $\mathrm{pH} 7$; however, this value did not change with increasing concentrations of SRFA (Kola and Wilkinson 2005). For C. kessleri, the electrophoretic mobility decreased slightly from $-2.9 \times 10^{-8}$ to $-3.05 \times 10^{-8} \mathrm{~m}^{2} \mathrm{~V}^{-1} \mathrm{~s}^{-1}$ when $30 \mathrm{mg} \mathrm{L}^{-1}$ of SRFA (Slaveykova et al. 2003) or $10 \mathrm{mg} \mathrm{L}^{-1}$ SRHA (Lamelas et al. 2005) was added to a cell suspension at $\mathrm{pH}$ 6. It might also be possible that the additional thickness of the $C$. reinhardtii cell wall was sufficient to prevent the formation of a ternary complex at the transport sites of the biological membrane or that its cell wall composition better screened (physically or chemically) the humic complexes. Unfortunately, further probing of the precise nature of the interaction between the humic substances (and their metal complexes) and the biological transport sites within the cell wall are beyond the scope of this paper.

\subsection{Pb Biouptake by the Two Algal Species Using Natural Organic Matter of the Laconnex Marsh}

Taking advantage from differences in "indirect" effect caused by DOM on Pb uptake by the two species in well control media, we would like to know whether such deviation is also observed in natural waters. In turn we hypothesis that differences observed may offer a way to evaluate under which condition, deviation from the BLM may occurs due to change in physicochemical properties of DOM. In order to more closely match natural environments, algae were indeed exposed to fresh marsh water ultrafiltrate fraction, its concentrated colloidal fraction and photoaltered colloidal fractions (Fig. 4). The organic matter of the colloidal isolate was qualitatively characterized using its fluorescence properties (Table 1). Based on its characteristic A and C peaks, but an absence of protein-like fluorophores (Baker 2001), it seems that it is mainly composed of humic-like components with an intermediate humification index of 18.3 (Table 1) (compared to 21.3 for the SRHA and 9.5 for the SRFA).

A decrease in $\left[\mathrm{Pb}^{2+}\right]$ was observed for the natural samples and was most pronounced in the presence of the organic concentrate ( $\mathrm{Col}$ and $\mathrm{Col}^{*}$; Fig. 4, red dots) and in agreement with the high carbon content of those samples. Photoalteration of the colloidal concentrate lead to an increase in $\mathrm{Pb}$ complexation, in contrast to previous studies using standard aquatic or soil humic substances (Spierings et al. 2011; Worms et al. 2015). Less complexation and a corresponding higher intracellular $\mathrm{Pb}$ content was found for algae exposed to the colloidal isolates as compared to the ultrafiltrate, for both algal species.

For $C$. reinhardtii, $\mathrm{Pb}$ internalization decreased in the presence of all three organic matter fractions with respect to the control containing no organic matter. Nonetheless, for the two colloidal fractions, biouptake was higher than predicted based solely upon the free ion concentrations. This result contrasted with the results obtained for the standard SRFA and SRHA (Fig. 2) and with results obtained for soil humic substances at the same pH (Worms et al. 2015). In natural water ultrafiltrate, it is possible that the competition of other metal ions at the uptake transport sites could explain the relatively larger decrease in bioaccumulation that was observed for that sample. Indeed, it is possible that the differences observed between results for the standard and natural samples could also be partly explained by the differences in the cationic composition of the different water fractions. 


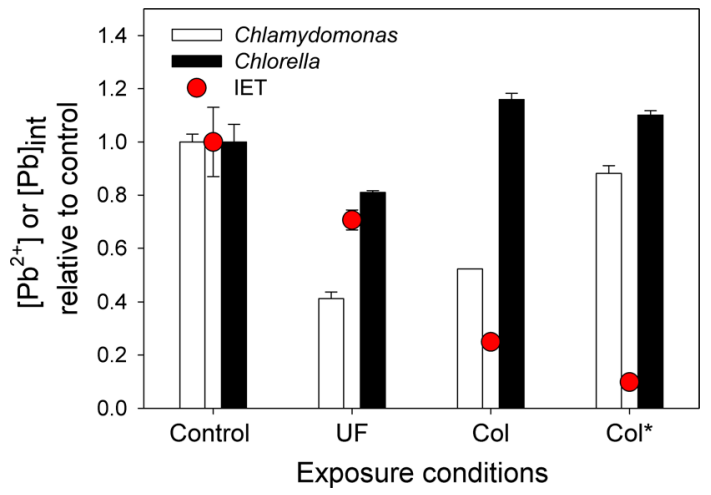

Fig. 4 Effect of natural water fractions on $\mathrm{Pb}$ uptake relative to control values in the absence of organic matter for $C$. reinhardtii (white bars) and C. kessleri (black bars). All solutions contained $[\mathrm{Pb}]_{\mathrm{tot}}=10^{-7} \mathrm{M}$ and are buffered to $\mathrm{pH} 7$ using $5 \times 10^{-3} \mathrm{M}$ HEPES. Organic matter concentrations are $\sim 5.4 \mathrm{mg} \mathrm{C} \mathrm{L}^{-1}$ (UF), $\sim 15.4 \mathrm{mg} \mathrm{C} \mathrm{L}^{-1}(\mathrm{Col})$ and $\sim 16 \mathrm{mg} \mathrm{C} \mathrm{L}^{-1}\left(\mathrm{Col}^{*}\right)$. Red points indicate the relative free ion concentration (measured by the IET)

For example, large differences in manganese concentrations between the three marsh samples were observed: $(1.02 \pm 0.03) \times 10^{-5} \mathrm{M}(\mathrm{UF}) ;(1.07 \pm 0.03) \times 10^{-6} \mathrm{M}(\mathrm{Col})$ and $(4.3 \pm 0.5) \times 10^{-7} \mathrm{M}\left(\mathrm{Col}^{*}\right)$. For this alga, it has been proposed that $\mathrm{Pb}$ is internalized via a copper transporter, for which Mn was an inefficient competitor (SanchezMarin et al. 2010b). The $\mathrm{Cu}$ concentration was higher in the colloidal concentrates, which was consistent with its strong complexation by natural organic colloids. Although calcium is also a known inhibitor of $\mathrm{Pb}$ internalization (Slaveykova and Wilkinson 2002), the small measured variability in its concentrations in the natural samples: $(9.8 \pm 0.3) \times 10^{-4} \mathrm{M}$ $(\mathrm{UF}) ;(7.6 \pm 0.3) \times 10^{-4} \mathrm{M}(\mathrm{Col})$ and $(8.7 \pm 0.3) \times 10^{-4} \mathrm{M}\left(\mathrm{Col}^{*}\right)$ could not account for the observed changes in $\mathrm{Pb}$ bioavailability. An alternative explanation could be that compounds other than humic-like components in the colloidal isolates affected the $\mathrm{Pb}$ bioavailability. Furthermore, following photoirradiation of the colloidal fraction, $\left[\mathrm{Pb}^{2+}\right]$ decreased but biouptake increased, suggesting that more complexes were formed but that these complexes were better able to contribute to biouptake. Indeed, small organic ligands have been shown in the past to be produced by photoalteration, rendering DOM more bioavailable (Brinkmann et al. 2003). Indeed, formation of small metal complexes may increase the bioavailability of metals by contributing more ternary complexes or by accidental transport of the metal complexes, as has been shown for other microorganisms [e.g., M citrate or M acetate (Errecalde et al. 1998; McLean et al. 2013)]. An "accidental transport" is likely to be found in natural waters, where carbon sources for microorganisms are very diverse. In our study, $C$. reinhardtii is grown heterotrophically using acetate as a carbon source. When acetate is present in exposure solutions, $\mathrm{Pb}$ uptake increases as compared to what would be expected based upon free $\mathrm{Pb}$ ion measurements alone (Worms IAM and Simon DS, personal communication) and consistent with an accidental transport of the complex. Overall, our results suggested that a more rigorous, molecular-level characterization of the natural colloidal pool and their photoproducts is necessary in order to accurately determine its role on $\mathrm{Pb}$ bioavailability to this alga.

For C. kessleri, biouptake was higher than predicted (by the free ion) for all organic fractions, although for the UF sample, it most closely corresponded with the measured decrease in $\left[\mathrm{Pb}^{2+}\right]$. Indeed, biouptake increased for colloidal concentrate by $30 \%$ when 
compared to the UF sample, even though free $\mathrm{Pb}$ decreased by $35 \%$ for $\mathrm{Col}$ and $60 \%$ for Col* fractions. Similar to the standard humic substances, for $C$. kessleri, the presence of natural humic substances enhanced the uptake of $\mathrm{Pb}$, although a slight decrease was observed when the colloids were photoirradiated, potentially due to the decrease in free $\mathrm{Pb}$ or a decrease in the adsorption of humic-like substances on the algal surface (Spierings et al. 2011). In the case of this green alga, these effects appear to greater than the competition effects that were observed for $C$. reinhardtii.

\section{Conclusions}

In the presence of standard humic substances (SRHA and SRFA), Pb biouptake by $C$. reinhardtii was accurately predicted on the basis of $\left[\mathrm{Pb}^{2+}\right]$ measured by an equilibrium ion-exchange technique in a simple synthetic medium. Nonetheless, this finding could not be generalized to a second algal species (C. kessleri), where uptake fluxes were much higher than expected by IET measurements. When the effect of fresh organic matter samples (marsh) were examined, $\left[\mathrm{Pb}^{2+}\right]$ was a poor indicator of $\mathrm{Pb}$ uptake, since biouptake generally much higher than that predicted by the free ion concentrations, for both algal species examined. Future research is clearly needed to better characterize, at the molecular and supramolecular level, the composition of DOM (both the nature of the organic ligands and role of the inorganic species) in order to better refine their interactions with the surface of microalgae and their potential roles in $\mathrm{Pb}$ uptake, bioavailability and toxicity.

Acknowledgments V.S. and I.A.M.W. gratefully acknowledge the financial support provided by Swiss National Science Foundation Project 200021-134627. K.J.W. acknowledges NSERC Discovery Grant funding. The assistance of Pr. Davide Vignati with the ultrafiltration setup and handling is greatly appreciated. Thanks are also addressed to the reviewers for their useful comments and suggestions.

\section{References}

Baker A (2001) Fluorescence excitation-emission matrix characterization of some sewage-impacted rivers. Environ Sci Technol 35:948-953

Bayen S, Worms I, Parthasarathy N, Wilkinson K, Buffle J (2006) Cadmium bioavailability and speciation using the permeation liquid membrane. Anal Chim Acta 575:267-273

Brinkmann T, Horsch P, Sartorius D, Frimmel FH (2003) Photoformation of low-molecular-weight organic acids from brown water dissolved organic matter. Environ Sci Technol 37:4190-4198

Campbell PGC (1995) Interactions between trace metals and aquatic organisms: a critique of the free ion activity model. In: Tessier A, Turner DR (eds) Metal speciation and bioavailability in aquatic systems. Wiley, New York, pp 45-102

Campbell PGC, Twiss MR, Wilkinson KJ (1997) Accumulation of natural organic matter on the surfaces of living cells: implications for the interaction of toxic solutes with aquatic biota. Can J Fish Aquat Sci $54: 2543-2554$

Cantwell FF, Nielsen JS, Hrudey SE (1982) Free nickel ion concentration in sewage by an ion-exchange column-equilibration method. Anal Chem 54:1498-1503

Coble PG (1996) Characterization of marine and terrestrial DOM in seawater using excitation emission matrix spectroscopy. Mar Chem 51:325-346

De Schamphelaere KAC, Nys C, Janssen CR (2014) Toxicity of lead ( $\mathrm{Pb})$ to freshwater green algae: development and validation of a bioavailability model and inter-species sensitivity comparison. Aquat Toxicol 155:348-359

Di Toro DM, Allen HE, Bergman HL, Meyer JS, Paquin PR, Santore RC (2001) Biotic ligand model of the acute toxicity of metals. 1. Technical basis. Environ Toxicol Chem 20:2383-2396 
Errecalde O, Seidl M, Campbell PGC (1998) Influence of a low molecular weight metabolite (citrate) on the toxicity of cadmium and zinc to the unicellular green alga Selenastrum capricornutum: an exception to the free-ion model. Water Res 32:419-429

Fortin C, Campbell PGC (1998) An ion-exchange technique for free-metal ion measurements $\left(\mathrm{Cd}^{2+}, \mathrm{Zn}^{2+}\right)$ : applications to complex aqueous media. Int J Environ Anal Chem 72:173-194

Fortin C, Caron F (2000) Complexing capacity of low-level radioactive waste leachates for ${ }^{60} \mathrm{Co}$ and ${ }^{109} \mathrm{Cd}$ using an ion-exchange technique. Anal Chim Acta 410:107-117

Ge Y, Sauve S, Hendershot WH (2005) Equilibrium speciation of cadmium, copper, and lead in soil solutions. Commun Soil Sci Plant Anal 36:1537-1556

Gonsior M, Peake BM, Cooper WT, Podgorski D, D’Andrilli J, Cooper WJ (2009) Photochemically induced changes in dissolved organic matter identified by ultrahigh resolution fourier transform ion cyclotron resonance mass spectrometry. Environ Sci Technol 43:698-703

Goodenough UW, Heuser JE (1985) The Chlamydomonas cell-wall and its constituent glycoproteins analyzed by quick-freeze, deep-etch technique. J Cell Biol 101:1550-1568

Guftavsson JP (2006) http://www.lwr.kth.se/English/OurSoftware/vminteq/

Hajdu R, Slaveykova VI (2012) Cd and Pb removal from contaminated environment by metal resistant bacterium Cupriavidus metallidurans $\mathrm{CH} 34$ : importance of the complexation and competition effects. Environ Chem 9:389-398

Harris EH (1989) Culture and storage methods. In: Stern DB, Witman G (eds) The Chlamydomonas sourcebook - a comprehensive guide to biology and laboratory use. Academic Press, San Diego

Hassler CS, Slaveykova VI, Wilkinson KJ (2004) Discriminating between intra- and extracellular metals using chemical extractions. Limnol Oceanogr-Methods 2:237-247

Jumarie C, Fortin C, Houde M, Campbell PGC, Denizeau F (2001) Cadmium uptake by Caco-2 cells: effects of Cd complexation by chloride, glutathione, and phytochelatins. Toxicol Appl Pharm 170:29-38

Kola H, Wilkinson KJ (2005) Cadmium uptake by a green alga can be predicted by equilibrium modelling. Environ Sci Technol 39:3040-3047

Kola H, Laglera LM, Parthasarathy N, Wilkinson KJ (2004) Cadmium adsorption by Chlamydomonas reinhardtii and its interaction with the cell wall proteins. Environ Chem 1:172-179

Kottelat R, Vignati DAL, Chanudet V, Dominik J (2008) Comparison of small- and large-scale ultrafiltration systems for organic carbon and metals in freshwater at low concentration factor. Water Air Soil Poll 187:343-351

Koukal B, Gueguen C, Pardos M, Dominik J (2003) Influence of humic substances on the toxic effects of cadmium and zinc to the green alga Pseudokirchneriella subcapitata. Chemosphere 53:953-961

Lamelas C, Slaveykova VI (2007) Comparison of $\mathrm{Cd}(\mathrm{II}), \mathrm{Cu}(\mathrm{II})$, and $\mathrm{Pb}(\mathrm{II})$ biouptake by green algae in the presence of humic acid. Environ Sci Technol 41:4172-4178

Lamelas C, Wilkinson KJ, Slaveykova VI (2005) Influence of the composition of natural organic matter on $\mathrm{Pb}$ bioavailability to microalgae. Environ Sci Technol 39:6109-6116

Lamelas C, Pinheiro JP, Slaveykova VI (2009) Effect of humic acid on Cd(II), Cu(II), and Pb(II) uptake by freshwater algae: kinetic and cell wall speciation considerations. Environ Sci Technol 43:730-735

McKnight DM, Boyer EW, Westerhoff PK, Doran PT, Kulbe T, Andersen DT (2001) Spectrofluorometric characterization of dissolved organic matter for indication of precursor organic material and aromaticity. Limnol Oceanogr 46:38-48

McLean JE, Pabst MW, Miller CD, Dimkpa CO, Anderson AJ (2013) Effect of complexing ligands on the surface adsorption, internalization, and bioresponse of copper and cadmium in a soil bacterium, Pseudomonas putida. Chemosphere 91:374-382

Mylon SE, Twining BS, Fisher NS, Benoit G (2003) Relating the speciation of $\mathrm{Cd}, \mathrm{Cu}$, and $\mathrm{Pb}$ in two Connecticut rivers with their uptake in algae. Environ Sci Technol 37:1261-1267

OECD (1984) Organization for Economic Cooperation and Development: guideline for testing chemicals. No. 201, Paris

Porcal P, Amirbahman A, Kopacek J, Novak F, Norton SA (2009) Photochemical release of humic and fulvic acid-bound metals from simulated soil and streamwater. J Environ Monitor 11:1064-1071

Ritchie JD, Perdue EM (2003) Proton-binding study of standard and reference fulvic acids, humic acids, and natural organic matter. Geochim Cosmochim Acta 67:85-96

Sanchez-Marin P, Beiras R (2012) Quantification of the increase in Pb bioavailability to marine organisms caused by different types of DOM from terrestrial and river origin. Aquat Toxicol 110:45-53

Sanchez-Marin P, Lorenzo JI, Blust R, Beiras R (2007) Humic acids increase dissolved lead bioavailability for marine invertebrates. Environ Sci Technol 41:5679-5684

Sanchez-Marin P, Slaveykova VI, Beiras R (2010a) Cu and Pb accumulation by the marine diatom Thalassiosira weissflogii in the presence of humic acids. Environ Chem 7:309-317 
Sanchez-Marin P, Santos-Echeandia J, Nieto-Cid M, Anton Alvarez-Salgado X, Beiras R (2010b) Effect of dissolved organic matter (DOM) of contrasting origins on $\mathrm{Cu}$ and $\mathrm{Pb}$ speciation and toxicity to Paracentrotus lividus larvae. Aquat Toxicol 96:90-102

Sanchez-Marin P, Bellas J, Mubiana VK, Ignacio Lorenzo J, Blust R, Beiras R (2011) Pb uptake by the marine mussel Mytilus sp. interactions with dissolved organic matter. Aquat Toxicol 102:48-57

Sanchez-Marin P, Fortin C, Campbell PGC (2013) Copper and lead internalisation by freshwater microalgae at different carbonate concentrations. Environ Chem 10:80-90

Schecher WD, McAvoy DC (1992) MINEQL ${ }^{+}$-A software environment for chemical-equilibrium modeling. Comput Environ Urban 16:65-76

Simon DF, Descombes P, Zerges W, Wilkinson KJ (2008) Global expression profiling of Chlamydomonas reinhardtii exposed to trace levels of free cadmium. Environ Toxicol Chem 27(8):1668-1675

Slaveykova VI, Wilkinson KJ (2002) Physicochemical aspects of lead bioaccumulation by Chlorella vulgaris. Environ Sci Technol 36:969-975

Slaveykova VI, Wilkinson KJ, Ceresa A, Pretsch E (2003) Role of fulvic acid on lead bioaccumulation by Chlorella kessleri. Environ Sci Technol 37:1114-1121

Spierings J, Worms IAM, Mieville P, Slaveykova VI (2011) Effect of humic substance photoalteration on lead bioavailability to freshwater microalgae. Environ Sci Technol 45:3452-3458

Sulzberger B, Durisch-Kaiser E (2009) Chemical characterization of dissolved organic matter (DOM): a prerequisite for understanding UV-induced changes of DOM absorption properties and bioavailability. Aquat Sci 71:104-126

Tercier-Waeber ML, Stoll S, Slaveykova VI (2012) Trace metal behavior in surface waters: emphasis on dynamic speciation, sorption processes and bioavailability. Arch Sci 65:119-142

van Leeuwen HP (1999) Metal speciation dynamics and bioavailability: inert and labile complexes. Environ Sci Technol 33:3743-3748

van Leeuwen HP, Town RM, Buffle J, Cleven R, Davison W, Puy J, van Riemsdijk WH, Sigg L (2005) Dynamic speciation analysis and bioavailability of metals in aquatic systems. Environ Sci Technol 39:8545-8556

Vigneault B, Campbell PGC (2005) Uptake of cadmium by freshwater green algae: effects of $\mathrm{pH}$ and aquatic humic substances. J Phycol 41:55-61

Vigneault B, Percot A, Lafleur M, Campbell PGC (2000) Permeability changes in model and phytoplankton membranes in the presence of aquatic humic substances. Environ Sci Technol 34:3907-3913

Worms IAM, Wilkinson KJ (2008) Determination of $\mathrm{Ni}^{2+}$ using an equilibrium ion exchange technique: important chemical factors and applicability to environmental samples. Anal Chim Acta 616:95-102

Worms I, Simon DF, Hassler CS, Wilkinson KJ (2006) Bioavailability of trace metals to aquatic microorganisms: importance of chemical, biological and physical processes on biouptake. Biochimie 88:1721-1731

Worms IAM, Parthasarathy N, Wilkinson KJ (2007) Ni uptake by a green alga. 1. Validation of equilibrium models for complexation effects. Environ Sci Technol 41:4258-4263

Worms IAM, Traber J, Kistler D, Sigg L, Slaveykova VI (2010) Uptake of Cd(II) and Pb(II) by microalgae in presence of colloidal organic matter from wastewater treatment plant effluents. Environ Pollut 158:369-374

Worms IAM, Adenmatten D, Miéville P, Traber J, Slaveykova VI (2015). Photo-transformation of pedogenic humic acid and consequences for $\mathrm{Cd}(\mathrm{II}), \mathrm{Cu}(\mathrm{II})$ and $\mathrm{Pb}(\mathrm{II})$ speciation and bioavailability to green microalga. Chemosphere. doi:10.1016/j.chemosphere.2014.10.093

Yamamoto M, Kurihara I, Kawano S (2005) Late type of daughter cell wall synthesis in one of the Chlorellaceae, Parachlorella kessleri (Chlorophyta, Trebouxiophyceae). Planta 221:766-775

Zsolnay A, Baigar E, Jimenez M, Steinweg B, Saccomandi F (1999) Differentiating with fluorescence spectroscopy the sources of dissolved organic matter in soils subjected to drying. Chemosphere $38: 45-50$ 